Italy: 'draconian' new law galvanizes demonstrations

SIR - Your News story 'New law threatens Italian research jobs' (Nature 455, 840-841; 2008) and Editorial 'Cut-throat savings' (Nature 455, 835-836; 2008) both describe the dire situation for research scientists in Italy. But that's only half the story.

The 4,000 researchers you cite belong only to research centres and include only researchers eligible to apply for permanent positions. Most temporary researchers in Italy are employed at universities under one of 20 or more different types of contract applicable to postgraduate and postdoctoral scholars. Neither the university administrators nor the ministry of education keeps track of this population, which the Italian network of temporary researchers, Rete Nazionale Ricercatori Precari, believes could consist of more than 60,000 people.

The present government's funding cuts to research and higher education are so drastic that Italy will fall short of the 2000 Lisbon Treaty requirements for government support of research and development across the European Union.

Although funds are available to hire 4,000 researchers, a law approved in August this year will withdraw this funding. Researchers already slated for jobs may lose the chance of a permanent position.

This law has galvanized demonstrations across Italy against the government's draconian measures. Students, technicians, permanent staff and temporary researchers have met to discuss the law and its consequences, with several faculties officially opposing the law. A petition has been set up at http://tinyurl.com/6otega.

Italian universities must change to become more responsive to international standards of research. But this governmental reform is not the change the universities need, assassinating as it will research and higher education in Italy.

Rete Nazionale Ricercatori Precari www.ricercatoriprecari.org e-mail: bologna@ricercatoriprecari.org Author's name and address supplied

\section{Italy: restoring axed funds is not enough to cure all ills}

SIR - The Italian government's proposed diversion of funds from scientific research to help boost the economy - discussed in your Editorial 'Cut-throat savings' (Nature 455, 835-836; 2008) - is lamentable. According to various independent surveys based on ISI Web of Science data, Italy's research productivity is already low and excellence is the exception rather than the rule.

One problem is stagnation. All Italy's universities are treated as equals and all academic staff are comparably paid. They jointly decide on all recruitment and promotion: if a position is available in an Italian zoology department, all the zoology professors will elect a commission that decides who shall take the post.

Another problem is that research resources are taken up by academics who only teach, rather than doing internationally recognized research. All have to teach 250 hours a year - fine if they are also doing research, but ridiculous if that is all they do. This may explain why it is hard to ascertain who just teaches and who (a numerous minority, but still a minority) does both teaching and research. It also explains why there is a marked resistance to the evaluation of scientific output, particularly from the unproductive areas. In the rare cases where evaluation is carried out, this is done entirely on impact factors, driving disciplines such as taxonomy towards extinction. (Paradoxically, Italian taxonomy is of international standard.)

The government may hope to create a new system in which teaching-only universities or departments, with no doctorate curriculum or research labs, are distinct from universities or departments that do both teaching and research. This idea has been discussed, but it would be risky and, knowing Italy, unlikely to be carried out effectively.

Restored funding alone would not be enough: we need to specify what we want for our university system. If the majority only teach, and their interests prevail in the allocation of resources, those who do both teaching and research will be the losers - along with Italy's research productivity.

Our brightest young postdocs leave for other countries because Italy holds no future for them. Money would be better spent on educating them if we then gave them the chance to work productively here.

Ferdinando Boero Dipartimento di Scienze e Tecnologie Biologichee Ambientali, Universitá del Salento, 73100 Lecce, Italy

e-mail:boero@unile.it

\section{Peer-reviewed parrot studies speak for themselves, as he did}

SIR - I take exception to Clive Wynne's Review of my book Alex \& Me: How a Scientist and a Parrot Discovered a Hidden World of Animal Intelligence - and Formed a Deep Bond in the Process (Nature 455, 864-865; 2008). As a memoir for a general audience, it does not contain in-depth technical detail. But Wynne's questioning of the underlying science is answered by my publications in the peer-reviewed literature one of which won the Frank A. Beach comparative psychology award (I. M. Pepperberg and J. D. Gordon J. Comp. Psychol. 119, 197-209; 2005).

Detailed controls were included against inadvertent cueing during 30 years' study of the cognitive and communicative abilities of
Alex, the African grey parrot; during testing, I never knew what Alex would be asked to identify in any trial. Because tests covered several different topics, neither Alex nor evaluators could target a particular subset of labels. Individuals never tested Alex on the labels they taught.

Wynne writes that the human ear is easily tricked, suggesting that Alex's responses were often not actual human labels. But incoherent responses were discarded as erroneous, and inter-observer reliability trials (with individuals from a different university listening to a video sound track) gave agreement above $90 \%$. Sonagraphic analysis showed that Alex's vocal patterns closely matched his human trainers' and were not "jumbled speech sounds".

Alex's idiosyncratic labels are overlooked in Wynne's review. The bird would use these irrespective of how a colleague or stranger might cue him otherwise. For example, toy cars and squares were always classed respectively as "truck" and "four-corner".

Replication failure was not a problem. Published data on my younger subjects detail a level of replication. Birds were presented with a barrage of training techniques, mostly different from those used with Alex, to determine which aspects of Alex's training engendered his success. These birds, with a quarter of Alex's exposure to the single, successful method, could not, by definition, achieve as much as Alex during the same time frame.

Wynne has no basis for implying that my methods might be flawed - other than a possible inherent scepticism, which, ironically, is a common bias discussed at length in the book.

Irene M. Pepperberg Vision Lab, Department of Psychology, Harvard University, Cambridge, Massachusetts 02138, USA e-mail: impepper@wjh.harvard.edu

Contributions may be sent to correspondence@nature.com, and will be edited. 